\title{
La reivindicación de Clitemnestra: la mujer polifónica en la obra dramática de Montserrat Roig
}

\author{
M. Àngels FRANCÉS DíEZ \\ Departament de Filologia Catalana \\ Universitat d'Alacant \\ angels.frances@ua.es
}

\begin{abstract}
RESUMEN
El objetivo de este estudio es situar en el contexto de principios de los noventa la única obra teatral de la escritora barcelonesa Montserrat Roig, "Reivindicació de la senyora Clito Mestres", y analizar su protagonista en relación a las conexiones que el nombre de Clitemnestra establece con los mitos clásicos. En la maraña de resonancias del monólogo se manifiesta la noción bajtiniana de polifonía y la de intertextualidad establecida por Kristeva, que explican la doble naturaleza de la voz de la señora Clito Mestres, quien reivindica y, a su vez, es reivindicada por la ambigüedad del mismo lenguaje que utiliza. Asimismo, examinaremos hasta qué punto las dimensiones literarias y espectaculares del género teatral nos invitan, en este caso, a una lectura más profunda del personaje, a establecer con ella una relación biunívoca más allá de los límites entre realidad y ficción.
\end{abstract}

Palabras clave: monólogo, teatro, polifonía, intertextualidad

[Recibido, marzo 2011; aprobado, junio 2011]

\section{Clytemnestra's claim: the polyphonic woman in Montserrat Roig's dramatic work}

\begin{abstract}
The aim of this study is to place the only theatrical work of the Barcelonian writer Montserrat Roig, "Reivindicació de la senyora Clito Mestres", in the context of the beginning of the nineties, and analyze her protagonist in relation to the connections that Clitemnestra's name establishes with the classical myths. Bakhtin's polyphony and Kristeva's intertextuality are concepts suitable to explain the double nature of Clito Mestres' voice, which claims and, in turn, is claimed by the ambiguity of the same language that she uses. Likewise, we will examine how the literary and spectacular dimensions of the theatrical genre invite us, in this case, to a deeper reading of the character, to establish with her a biunique relationship beyond the limits between reality and fiction.
\end{abstract}

Keywords: monologue, theatre, polyphony, intertextuality 


\section{Introducción}

El objetivo de este estudio es situar en el contexto de principios de los noventa la única obra teatral de la escritora barcelonesa Montserrat Roig, "Reivindicació de la senyora Clito Mestres", y analizar su protagonista en relación a las conexiones que el nombre de Clitemnestra establece con los mitos clásicos y a la estructura polifónica que presenta la obra. En la maraña de resonancias del monólogo se manifiesta la noción bajtiniana de polifonía y la de intertextualidad establecida por Kristeva, que explican la doble naturaleza de la voz de la señora Clito Mestres, quien reivindica y, a su vez, es reivindicada por la ambigüedad del mismo lenguaje que utiliza. De hecho, el mismo título del monólogo parece sugerir una primera interpretación según la cual ella es la que reivindica el personaje que interpreta, el de Clitemnestra. Sin embargo, la ambigüedad de la preposición de en el sintagma invita a una segunda lectura, como en un palimpsesto: ella, Clito, es el personaje que l'autora reivindica. Para terminar, examinaremos hasta qué punto las dimensiones literarias y espectaculares del género teatral nos invitan, en este caso, a una lectura más profunda del personaje, a establecer con ella una relación biunívoca más allá de los límites entre realidad y ficción.

\section{Roig en la escena catalana}

Aunque la trayectoria literaria de Montserrat Roig está inequívocamente unida al género narrativo, su vinculación al mundo teatral se remonta a principios de los sesenta, cuando ingresa en la Escuela de Arte Dramático Adrià Gual animada por su padre, Tomás Roig i Llop, y siguiendo el ejemplo de su hermana Glòria, e inicia así un breve itinerario como actriz que, en cualquier caso, no pasa del ámbito amateur. No obstante, es en este contexto donde comienza y afianza relaciones que resultarán fundamentales para su futuro, tanto en el ámbito personal como literario: hablo de Maria Aurèlia Capmany, Pilar Aymerich o Josep Maria Benet i Jornet, por citar sólo algunos de los nombres más significativos. Este último recuerda, en sus memorias, una referencia al teatro en una de sus cartas: "Tinc moltes ganes que comenci l'any que ve per començar seriosament lo del teatre. [...] Crec que és important que ens ho plantajem amb una forta base ideològica..." (Benet 2010:128). Su vinculación con la EADAG, pues, se explica como parte de su incesante búsqueda de vías de expresión y reivindicación de su lugar en el mundo, como voz de una generación asumió como propias las nociones de compromiso y lucha por la democracia que, años después, se instauraría lentamente en el país.

Si bien siempre mostró su interés por el texto dramático, e incluso manifestó en repetidas ocasiones su deseo de hacer incursiones en el género (Benet 2010:159), no es hasta mediados de los ochenta que escribe un guión para televisión, "El mateix paisatge", y, más tarde, su primer y único monólogo teatral, "Reivindicació de la senyora Clito Mestres", que se estrena en el teatro Romea 
de Barcelona en 1991, protagonizado por Glòria Roig, y se repone luego en la Sala Beckett. La obra es resultado de un encargo de Domènec Reixach, director entonces del Centre Dramàtic Nacional, quien "decideix proposar a escriptors que no han escrit teatre que es plantegen un monòleg. Si la cosa funciona, si així els pot comunicar les ganes de continuar i d'escriure després, encara, altres textos més complicats..." (Benet 2010:161). Roig acepta aunque ya han empezado los problemas de salud que, poco tiempo después, acabarían de manera abrupta con su vida. Una de sus últimas apariciones públicas es, precisamente, en el escenario del Romea y de la mano de su hermana, bajo un largo aplauso que no sólo valora la obra sino, también, su lucha contra la enfermedad.

El monólogo objeto de estudio se inscribe, pues, en medio de iniciativas varias del circuito teatral catalán para fomentar y proyectar la dramaturgia autóctona:

L’operació —anomenada popularment "operació Belbel"- dóna fruits. El canvi és del tot sorprenent. El CDGC, dirigit per Domènec Reixach, defineix la seva línia artística en relació amb el teatre català, cosa que suposa una política decidida de revisió dels clàssics, l'estrena de diversos autors contemporanis [...], el muntatge dels últims premis Ignasi Iglesias [...] i l'oferta de beques a la creació de noves obres. Alguns narradors consolidats també s'interessen pel teatre i obtenen facilitats per estrenar al CDGC. És el cas de Manuel Vázquez Montalbán, Montserrat Roig o Eduardo Mendoza (Batlle 2006:82).

Asimismo, se hace eco de la forma y las preocupaciones del momento. Primero, por el tipo de texto elegido, el monólogo: "la crisi del diàleg esdevé absoluta, s'entronitza el monòleg com a forma preeminent" (Batlle 2006:87). Y segundo, por la esencia polifónica, fragmentaria, de su personaje principal: "els locutors d'aquest monòleg són individus 'escindits', que sempre 'dialoguen' amb ells mateixos" (Batlle 2006:87). En consonancia con la obra de autores franceses de los setenta, el monólogo escrito por Roig se podría calificar "de 'volum de silenci dels mots', de 'crepuscle del diàleg', o de 'monòleg a diferents veus'" (Batlle 2006:88). Precisamente sobre esta polifonía descansa no sólo ésta, sino también otras obras de Roig.

\section{La revisión de un texto clásico: sobre polifonías y otras cuestiones}

Las nociones de polifonía y alteridad (Bajtín 1981) sirven de base a la crítica Elaine Showalter (1986) para analizar en la literatura contemporánea el reflejo de las vidas de las mujeres en la sociedad. La definición dialógica del yo efectuada por Bajtín, que lo presenta no como entidad, sino como relación cambiante entre el ser y el otro, explica hasta qué grado las identidades femeninas están fracturadas o divididas: como los sujetos colonizados, son las otras, las silenciadas, convertidas en objetos y fuera del discurso y la cultura dominantes 
(masculina y blanca). Las mujeres sujeto, como los sujetos coloniales, escriben dentro y contra este proceso de alterización.

Así pues, Showalter usa la noción bajtiniana de discurso de doble voz como marco para analizar la alteridad de la escritura de las mujeres dentro de la sociedad patriarcal, y no como un mundo aparte:

A recognition of the dialogic, double-voiced nature of discourse, allows Showalter and other feminists to cease in the exploration of the wholly 'other' tradition of writing, and to begin exploring the manner in which the writing of women, along with other marginalized groups, is always a mixture of available discoursive possibilities (Allen 2000:160).

La obra literaria de Montserrat Roig, y en especial el monólogo que nos ocupa, es buena muestra de ello. Su literatura es una polifonía de voces que, como el palimpsesto de que habla Genette (1982), tiene sucesivas capas de significado, invita a dobles lecturas, a juegos e ironías que, entre líneas, transmiten un mensaje distinto del oficial:

La literatura, a mi parecer, todavía tiene una función que nada puede sustituir: la de liberar las voces del mundo, las voces antiguas frente a la VOZ, la que brota en el altar de nuestros hogares, la que coacciona nuestra imaginación, privándonos de la libertad de soñar por cuenta propia (Roig 1989:80).

La polifonía de Roig no es solamente perceptible como un coro de voces estridentes, las de personajes originados en el lenguaje, que viven a través de él: también en la revisión, apropiación y transformación de textos anteriores se puede apreciar su particular subversión del discurso establecido. Según Julia Kristeva (1980:36),

The text is $[\ldots]$ a productivity, and this means: first, that its relationship to the language in which it is situated is redistributive (destructiveconstructive) $[\ldots]$; and second, that it is a permutation of texts, an intertextuality: in the space of a given text, several utterances, taken from other texts, intersect and neutralize one another.

Así pues, en todo texto se da un proceso de creación del significado a partir del diálogo entre una serie de sistemas en conflicto, empezando por el mismo signo lingüístico, que no es un punto con significado fijo, sino un lugar atravesado por redes y superficies textuales diversas (Bengoechea 1997:5-6). El significado no está: se elabora en un contexto histórico y social determinado, fundamental para el proceso. La intertextualidad establece un vínculo entre el texto y la sociedad en que se genera, ya sea a través de estrategias distanciadoras, cuestionando puntos de vista articulados o modelando tácticas de resistencia. El término desafía, así, la concepción tradicional romántica de la creación literaria 
- como producto de un autor aislado y original — y la percepción formalista del texto como entidad cerrada y autónoma: Kristeva lo sitúa entre la apropiación y la influencia de textos anteriores, más allá de la cita, el pastiche, la imitación o el plagio. ${ }^{1}$

En "Reivindicació de la senyora Clito Mestres", Roig revisa un texto clásico, la tragedia de Séneca Agamemnon, y nos ofrece una nueva lectura, creando una compleja telaraña de discursos y textos que activan en la mente del lector toda una serie de asociaciones y expectativas, sobre todo en el ámbito de los símbolos y la mitología. ${ }^{2}$ Así, la obra, como espacio de producción de ideologías, interpela al lector $y$, de alguna manera, lo transforma: "Las re-acentuaciones de los textos maestros nos dan que pensar, y ponen de manifiesto que el proceso comunicativo es uno de interacciones. No estamos encerrados en la 'jaula de hierro' de una sola subjetividad" (Zavala 1996:197). Y precisamente contra esta subjetividad única orienta Roig, como hemos visto anteriormente, su quehacer literario.

\section{El teatro, espacio boomerang}

Si la negociación de significado entre autor y lector es cierta para todo texto literario, en el género teatral es especialmente compleja. Barthes lo define como una máquina cibernética, que transmite una complicada polifonía informacional: el espectador teje la red de significados a partir de significantes que no se limitan a la palabra, sino que incluyen también el decorado, los gestos, la mímica, que pueden permanecer inmóviles o cambiar con las idas y venidas de los personajes (Abellán 1983:12).

A la densidad de significantes propia del género, se añade su carácter híbrido. M. Carmen Bobes define así el texto dramático:

el conjunto de la obra escrita y la obra representada, con todas las relaciones suscitadas en el proceso de comunicación en dos fases: lectura y representación, y distinguimos en él dos aspectos (no dos partes o fases), el Texto Literario y el Texto Espectacular; el primero se dirige a la lectura, el segundo a la representación, pero ambos están en el texto escrito y en la representación; en el texto escrito todo está bajo expresión lingüística; en la representación el texto literario se conserva en forma de palabra (diálogo principalmente), y el texto espectacular en forma de signos verbales (diálogo) y no-verbales. (1997: 12)

\footnotetext{
${ }^{1}$ El concepto de intertextualidad tiene, por lo tanto, una doble vertiente: por una parte, se refiere al signo literario como producto de una serie de influencias sociales e ideológicas concretas y, por otra, a la reapropiación revolucionaria de textos anteriores.

${ }^{2}$ La revisión que efectúa Roig en este monólogo va en la línea de otras obras que se proponen ofrecer visiones alternativas de la mitología clásica, como la Clitemnestra de Maria Josep Ragué Arias, pieza teatral en catalán de 1986 que recrea y reivindica la tragedia del mismo personaje que Roig homenajea en su monólogo.
} 
Así pues, es teatro la obra literaria escrita para ser representada y, también, todo el proceso de su representación. Tiene, por lo tanto, una doble dimensión, la literaria y la espectacular, envueltas ambas en el proceso dialógico entre autor y espectador. ${ }^{3}$ Este proceso es interactivo y circular: se inicia en el emisor, el autor $\mathrm{y}$, por medio de una forma, lleva un mensaje, la obra, hasta el receptor (hasta aquí sería lineal); sin embargo, el efecto feedback describe el camino contrario, pues va del receptor (espectador) al emisor (autor, director, actores) y condiciona la obra en sus formas y en su sentido. El hecho de que la recepción final sea pública y colectiva ha sido tenido en cuenta por el autor, que da formas especiales a su obra para que el espectáculo sea posible. El texto literario es anterior a la representación y tiene ya los diálogos y las acotaciones que se materializarán en la puesta en escena: la obra incluye un lector virtual, pero también un espectador virtual y una teatralidad, pues está dispuesto para convertirse en espectáculo. Bobes (1997: 28-30) insiste en el hecho de que el lector interpreta pero deja siempre intacto el texto. Es decir, el texto dramático penetra en la representación, pero ésta nunca penetra en el texto dramático. Las variantes de la puesta en escena son circunstanciales, nunca definitivas. Sin embargo, el texto de Roig invita a establecer una doble vía de redención, que va del personaje al espectador y vuelve, como un boomerang, para establecer otro final, para ser un comienzo.

Veamos pues de qué manera se manifiesta la intertextualidad -respecto al dialogismo del lenguaje, a la revisión textos anteriores y a la transducción del texto literario en representación — en la obra teatral de Montserrat Roig.

\section{El monólogo}

Como ya hemos comentado en páginas anteriores, Montserrat Roig sentía verdadera pasión por el teatro desde sus primeras experiencias como actriz en 1'Escola d'Art Dramàtic Adrià Gual. La escritura dramática, sin embargo, era una especie de asunto pendiente en su trayectoria literaria: ella nunca dejó de asegurar que algún día, sí, pero su labor como periodista y narradora no le dejaba mucho margen de tiempo para dedicarse a otras formas de contar. En el prólogo a la edición de 1992, cuenta Josep Maria Benet i Jornet que "ella es trobava embarcada en una més que satisfactòria carrera de novel-lista. No crec que, de manera fonamental, trobés a faltar l'ús d'una altra manera d'explicar-se" (Benet i Jornet 1992: 9).

\footnotetext{
${ }^{3}$ Según el modelo semiótico lineal de análisis de una obra teatral, "el Autor inicia un proceso de comunicación que se materializaría en la obra (acabada en su forma y abierta en su sentido) y culminaría en el Lector que la interpretaría en una "lectura" coherente y personal. El Lector puede iniciar otro proceso que sería de transducción: constituyéndose en Director de escena, propone su propia lectura como un nuevo mensaje que se representa escénicamente y se dirige a un público o espectador de carácter colectivo" (Bobes 1997: 18).
} 
Aún así, y gracias al encargo del Centro Dramático, Montserrat realizó su antiguo deseo de manejar el lenguaje dramático y demostró, en palabras de Benet i Jornet, que sabía expresarse escénicamente. Y aunque no eligió ni la forma ni la extensión del texto, su estructura encaja perfectamente con la polifonía de las novelas y los cuentos de la autora, si entendemos el monólogo como el "parlament d'un personatge que està sol, que es creu sol o que, estant en presència d'altres, parla al marge de ser escoltat" (Abellán 1983:84). La soledad de personajes marginales, que se saben solos y cuyas voces son silenciadas, es uno de los ejes temáticos que vertebran la literatura de Montserrat Roig.

\subsection{La historia de Clito Mestres}

Un escenario fijo, el camerino de una actriz, establece ante el espectador una primera referencia metatextual: el teatro dentro del teatro. ${ }^{4}$ Los minutos previos a una representación teatral completan el cronotopo que sirve de marco al monólogo. En el camerino se pueden observar varios objetos: un traje, una peluca, maquillaje. Atuendos para disfrazar una identidad de otra, elementos carnavalescos que anuncian un juego de máscaras. Se produce la entrada del único personaje, Clito Mestres, "vestida de manera adotzenada" (Roig 1992:21), con el pelo recogido en un discreto moño en la nuca y una traje chaqueta más bien anodino. Se mueve inquieta, un poco aturdida, mientras trata de recordar una serie de tareas cotidianas, domésticas, que le quedan pendientes en el mundo exterior. El rostro y la mirada de Glòria Roig, hermana de la autora - para quien el monólogo fue escrito- tienen ese aire familiar que parece recordar a Montserrat Roig, cuya presencia se deja notar detrás y sobre el escenario.

El personaje Clito, en la antesala de la escena, a punto de abandonar el mundo real, recita fragmentos del papel que va a representar, el de Clitemnestra, dudando de su propia capacidad para declamar sus palabras. Mientras se toma una copa de Jerez, que ha traído envuelta en papel dentro del bolso, recuerda la trayectoria vital que la ha llevado al momento presente: su infancia, marcada por la figura de un padre tierno y protector; sus primeras incursiones en el mundo del teatro — que incluyen la usurpación de un papel de Electra ${ }^{5}$ en su juventud-, su matrimonio con Hans, el alemán que le habla de orquídeas y se la lle-

\footnotetext{
${ }^{4}$ Las referencias que, en lo sucesivo, haré a la puesta en escena del monólogo pertenecen a una grabación realizada en los estudios de TVE de Sant Cugat, bajo la dirección de Mercè Vilaret, que fue emitida por La 2 el día 17 de noviembre del 2001. Me ha sido imposible localizar una copia de la representación que tuvo lugar en el teatro Romeu y la sala Beckett: no figura en los archivos del Teatre Nacional de Catalunya.

${ }^{5}$ La figura de Electra, que en Agamemnon instiga a su hermano Orestes para que mate a su madre, también encuentra resonancias en el personaje de Clito Mestres, muy unida a su padre, al cual recuerda bondadoso y protector. Herr Hans le explica que el comportamiento de Electra en la tragedia clásica se explica porque está enamorada de Agamenón, pero Clito opina que tales interpretaciones no son más que "Falòrnies. Els versos són d'allò més bonic i, quan fas teatre, no penses en tanta complicació" (Roig 1992: 24). El episodio de Electra y Orestes conspirando contra Clitemnestra recuerda también el poema de "Amor de mare", con un argumento similar.
} 
va a Hamburgo... La mirada se le nubla al recordar la espesa niebla de la ciudad, que sólo se empieza a disipar con el nacimiento de su hija. Las infidelidades de Hans con mujeres anónimas se suceden, hasta que la figura de la otra toma un perfil y un nombre concretos: el de Helena. La muerte de la niña indirectamente causada por Hans - y presumiblemente Helena - en un viaje de esquí sume a Clito de nuevo en la niebla hasta que conoce a Helmut, un amante dulce que le pide que represente el único papel que no sabe llevar a cabo: el de ella misma. Cuando Hans lo descubre, la perdona, la perdona cada día a la hora del desayuno. Con el tiempo vuelve a quedarse embarazada y da a luz gemelos, un niño y una niña, que crecen ajenos a ella: él quiere ser rico, y ella se enamora de hombres casados que la tratan muy bien. Un día, después de la muerte de su padre, decide dejarlo todo y volver con su madre, enferma y sola. De nuevo en casa, conoce a Sofía, una directora de teatro que le devuelve la pasión por la escena y le otorga el papel de Clitemnestra, su reivindicación.

\section{Clitemnestra entre los personajes femeninos de las tragedias griegas}

Como es bien sabido, el imaginario femenino de la cultura occidental tiene una doble tradición: la herencia judeocristiana y la cultura clásica. Ante la polarización de Eva vs. María (hada/bruja, dama/prostituta, musa/mujer fatal...) preconizada por la primera, la segunda construyó una amplia galería de personajes femeninos de gran riqueza y complejidad simbólica, de naturaleza polifacética, que contrasta con la imagen homogénea de la figura del héroe. Des de Pandora hasta Penélope, pasando por Antígona i Medusa, los personajes femeninos de los clásicos griegos representan mejor que nadie las tensiones de la condición humana, sus claroscuros, la ambigüedad, la fidelidad y también su rebelión (Madrid 1998:51-59). Los personajes femeninos dibujados por Séneca se pueden clasificar en dos grupos: las mujeres que están todavía o han superado ya la edad de la fecundidad, cumpliendo en su presente o en su pasado con esa finalidad reproductora que de ellas espera la sociedad patriarcal (Deyanira, Clitemnestra, Megara, Andrómaca, Fedra, Yocasta, Alcmena, Hécuba) y las vírgenes, que reciben un tratamiento menos elaborado (Antígona, Políxena, Casandra, Electra). Asimismo, se dividen en prototípicas (casta, pia, lanifica, pudica, uniuira, mater) y antiprototípicas, que se desvían de la norma y reciben, por lo tanto, el castigo que merece su desafío (López 1995:75-76). Entre éstas se encuentra Clitemnestra, probablemente uno de los personajes femeninos más denostados de toda la literatura griega.

La tragedia de Séneca Agamemnon, basada en la obra homónima de Esquilo, gira en torno al regreso de Agamenón a Micenas, después de acabar la guerra de Troya, y el trágico desenlace que allí le espera. En su ausencia, su esposa Clitemnestra ha entablado relación con Egisto, y ambos le asesinan a su regreso. Electra salva a su hermano Orestes de una muerte segura, y es recluida. Casandra, troyana concubina de Agamenón, víctima del odio y de los celos de Clitemnestra, también muere por una orden de ésta. 
En la tragedia, Clitemnestra es hermana de Helena, otra de las heroínas antiprototipo que, con su desviación de la norma, han provocado la tragedia de todo un pueblo. Además, como nota Aurora López (1995:86), el comportamiento de Clitemnestra se parece al de Juno: al igual que la diosa, justifica su acción vengadora por la presencia de la concubina de su esposa en el palacio. Para la protagonista del monólogo de Roig, Casandra es la joven "que ho sap tot, entenimentada, que ho preveu tot..." (Roig 1992:37), que en su tragedia particular lleva el nombre de Helena, "una gasela del Poble Sec," universitaria, que seduce a los hombres y los aparta de su hogar.

Otra poderosa razón de Clitemnestra que justifica su odio a Agamenón es que éste, para obtener la bonanza de los vientos en su travesía a Troya, ofrece a su hija Ifigenia en sacrificio a los dioses. Este factor, que en monólogo de Roig es fundamental para explicar la desesperación de la protagonista, es mencionado de pasada en las versiones del mito: de hecho, la mayoría presentan a Clitemnestra como una madre desnaturalizada, que muere a manos de su hijo Orestes. Sin embargo, es precisamente el amor por Ifigenia lo que provoca las primeras acciones de Clitemnestra: "l'Agamèmnon, que és el marit, ofrena la filla als déus, el pare mata la filla, el pare mata la filla... (pausa)" (Roig 1992:37). En la escena, el tono con que la actriz pronuncia la última frase denota cómo, de repente, Clito cae en la cuenta del dolor que le une a su personaje; la pausa tras la repetición enfatiza aún más su identificación. Clito realiza así el deseo de Roig, que en Digues que m'estimes encara que sigui mentida (1991:85) defendía la necesidad de revisar las figuras femeninas de la mitología clásica: "La identificació ha de ser poètica, allò que no trobem aquí, però que és posible, a través de la paraula, dins l'univers imaginari". En el universo imaginario que proporciona el teatro, pues, es donde Roig actualiza el mito y presenta su versión de Clitemnestra:

La meva Clitemnestra és una dona que té un marit que se'n va a una guerra que ella no entén, una mare que veu com el seu home li arrabassa la filla per oferir-la als déus en immolació i que es troba que aquest mateix home torna de la batalla amb una noia jove i intel-ligent. La meva Clitemnestra és una dona de finals de segle XX (Roig 1991:86).

En una tercera vía intertextual, Roig relaciona el mitema del asesinato de Clitemnestra a manos de Orestes con un poema de Jacint Verdaguer, "Amor de mare",, pero sugiere que el corazón de su personaje no es como el de la madre del poema que, después muerta, todavía late por él. No: el personaje que interpreta Clito quiere explicarse, quiere justificar sus acciones, tomar la palabra y reivindicar su derecho a la rabia:

\footnotetext{
${ }^{6}$ El poema cuenta la historia de lo dolent fill (el mal hijo) que, en prueba de amor a la dolenta filla (la mala hija), le arranca a su madre el corazón y se lo lleva en ofrenda; por el camino, tropieza, y el amante corazón aún le pregunta si se ha hecho daño.
} 
Vull explicar-me. Sí, quan una dona és malvista, el seu llenguatge sempre té agror.

Pel que m'afecta, és una injúria. Cal saber els fets; si doncs mereixen l'execració,

bé que es detestin; i si no, per què odiar? (Roig 1992:37)

Las primeras versiones del mito exculpan a Clitemnestra porque la presentan seducida por Egisto: el hombre es el móvil del comportamiento de la heroína, cuyas dudas se resuelven a favor del mal. Para Clito, sin embargo, el amante de su personaje no tiene autoridad alguna: "un mitja cerilla, al capdavall" (Roig 1992:37). Su Clitemnestra tiene las riendas de su destino: "El crim de Clitemnestra, una de les més bescantades de les dones tràgiques, és que va voler actuar com un home, va voler decidir el seu destí” (Roig 1991: 87).

La venganza de Clito Mestres contra su mediocre Agamenón no tiene lugar en el mundo real, sino en el escenario. Tal como explica Benet i Jornet en el prólogo a la obra, a medida que Clito se desnuda de su ropa cotidiana y se viste de Clitemnestra, va tomando seguridad en su papel, se convierte, por breves y gloriosos momentos, en la heroína trágica que reivindica su derecho a la palabra. Sin embargo, el teatro es sólo un sueño, una ficción: su vida se entrelaza con la del texto que representa, pero el texto no redime su fracaso. Cuando acabe la función, y en palabras de Benet i Jornet (1992: 16),

tornarà a ser la dona de classe mitjana ocupada i preocupada per petites coses que no sabem si de debò arriben a interessar-la. [...] A Clito Mestres sols la salva, durant una estona, el teatre. El poder salvador del teatre, ni que sigui provisional, queda expressat amb vehemència, no pas en les paraules del personatge, sinó molt millor, molt més subtilment i més profundament, en l'efecte de la representació damunt una patètica Clito Mestres que durant l'estona de la representació es transforma i es realitza, i que durant un instant màgic, escapa al seu destí.

\section{Clito Mestres y el doble lenguaje}

Según Bakhtin, el yo es polifónico por definición, y se comunica en una amalgama de voces que provienen de contextos sociales y orígenes diversos. Somos nosotros, nunca el yo individual, autónomo (Zavala en Adell 1998:418) La identidad de una actriz como Clito Mestres, sin embargo, es todavía más poliédrica, si cabe, porque en ella se amalgaman sus voces como ser cultural múltiple y, además, las de los personajes que representa, con los cuales establece una fructífera simbiosis.

Su relación con el lenguaje en el mundo real es problemática: "i és que jo, de petita, en lloc de dir autobús, deia aubotús, i mànica en lloc de màquina..." (Roig 1992:25). Su mismo nombre es fruto de esta inconsciente manipulación 
de las letras: Clotilde deriva en Clito, y lo que es motivo de burla entre los otros, significa para ella un nuevo bautizo, que su padre legitima asociándolo a la figura mítica del mismo nombre que, siendo mortal, fue colocado entre los dioses por Aurora, tal era su belleza. Sin embargo, las resonancias simbólicas del nombre van más allá de esta explicación: Clito hace alusión, también, a la palabra clítoris, que asociaría con el personaje la reivindicación de su sexo, de su derecho al deseo, porque es precisamente con su amante Helmut cuando, sin máscaras ni palabras prestadas, llega a un largo orgasmo y es ella la que grita: "era jo que cridava, la Clito que cridava. (Ho repeteix en veu baixa.) La Clito que cridava" (Roig 1992:33).

Volviendo al lenguaje, es en el escenario donde Clito Mestres experimenta una doble transformación: cuando se viste de un personaje, adquiere también su voz, y se vuelve dueña de las palabras: “A l'escenari, no m'equivocava mai. Em sortien les paraules, les unes enllaçades amb les altres. Perfectes. A l'escenari, jo enraonava com si un altre enraonés per mi" (Roig 1992:25).

Clito renace a través de lenguajes prestados, y por breves instantes vive a través de ellos. En ella coexisten las sucesivas metamorfosis escénicas y su propia voz, la más muda de todas, consecuencia de su pérdida de ilusión en el mundo real. Cuando pierde a su hija, pierde también el habla: "I jo no parlava amb ningú" (Roig 1992:31). El dolor, que es incompatible con el teatro (Roig 1992:30), no se encuentra en el sonido, sino en el silencio: "I en Hans es va endur l'Iris, que encara semblava més boleta amb l'anorac blau cel i la gorreta blanca. Se la va endur, se la va endur ( $F$ a com si anés a xisclar i s'agafa el ventre ben fort. Calla durant una estona) (Roig 1992:30).

Durante un tiempo, sin embargo, el dolor se disipa en los ojos de un amante, Helmut, que la ve en su múltiple esencia: "Una dona que ha fet teatre és una dona singular... És... totes les dones" (Roig 1992:33). Ella se transforma para él en sucesivos juegos amorosos, pero cuando le pide que sea ella misma, Clito no sabe dónde buscar:

Jo no vaig contestar però vaig tardar tres hores a ser jo, perquè no sabia com jo havia de ser jo. Però, al final, em va surtir un crit i vaig morir-me una mica $\mathrm{i}$ aleshores vaig ser jo, vaig ser jo i no em va venir a la memòria cap poema. (Roig 1992:33)

Un grito la libera, como a la Natàlia de La plaça del diamant de Mercè Rodoreda. Sin embargo, la voz de Hans, su marido, la devuelve al papel que le corresponde y abandona a Helmut, que reconoce la derrota de los dos: "Una dona com tu..., només hi ha un paper que no és capaç de fer" (Roig 1992:34). El suyo propio. Ahora, Clito sólo vive de la memoria, de las voces del pasado, que existen a través de ella: "Ho recordo tot, si no ho recordo jo, qui ho recordarà?" (Roig 1992:36). 


\section{Conclusiones provisionales}

El monólogo de Roig presenta la alineación de un personaje principal, Clito Mestres, que aprende a verse y a construirse socialmente a través del lenguaje de los otros. Es un sujeto colonizado por su marido, Hans, que la encadena a un papel del que no puede escapar. Las sucesivas máscaras que interpone entre ella y el mundo la relacionan con la noción carnavalesca de Bajtín. Sólo gracias al amante que la ve en su pluralidad, recupera en el deseo la palabra que había perdido y se encuentra a sí misma, aunque sólo por un breve tiempo: la voz del marido la devuelve al lugar que le corresponde. En el escenario, sin embargo, Clito Mestres ocupa una posición de resistencia, como la antiprototípica Clitemnestra, revisando el mito, declamando un discurso alternativo, no oficial, desde una posición de sujeto. Establece así con el lector i/o espectador el juego dialógico entre lenguajes silenciados en el pasado: le interpela, le insta a reinterpretar nociones asumidas, a ser el artífice de su redención.

¿Sería ingenuo imaginar para Clito otro destino, quizá como actriz? ¿Imaginarle una salvación real a través del texto dramático? Seguramente sí, aunque como lectores/espectadores tenemos el derecho de crear para ella un final diferente, cerrando con sus mismas palabras, que acaban con un comienzo: "I, ara, sortiré a l'escenari i diré les paraules de Clitemnestra. Que tothom em miri, que tothom m'escolti, que la senyora Clito Mestres és a punt de començar" (Roig 1992:38).

\section{Bibliografía}

ABELLÁN, Joan (1983): La representació teatral. Introducció als llenguatges del teatre actual. Barcelona: Institut del Teatre.

ALLEN, Graham (2000): Intertextuality. Londres: Routledge.

BAJTíN, Mijaíl (1981): The Dialogic Imagination: Four Essays by M. H. Bakhtin. Carril Emerson y Michael Holquist (trad.), Austin, Texas: University of Texas Press.

BATLLE, Carles (2006): "Drama català contemporani: entre el desert i la terra promesa", en L'escena del futur. Memòria de les arts escèniques als Països Catalans (1975-2005), Francesc Foguet - Pep Martorell (coord.), Vilanova i la Geltrú: El Cep i la Nansa, pp. 75-102.

BENET I JORNET, Josep M. (1992): "Pròleg" a Reivindicació de la senyora Clito Mestres. Seguit de El mateix paisatge. Montserrat Roig, Barcelona: Edicions 62, pp. 7-17.

BENET I JORNET, Josep M. (2010): Material d'enderroc. Barcelona: Edicions 62. BENGOECHEA, Mercedes (1997): "Introducción" a Intertextuality/Intertextualidad. Mercedes Bengoechea - Ricardo Sola, Alcalá de Henares: Servicio de Publicaciones de la Universidad de Alcalá, pp. 1-13. 
BOBES, M. Del Carmen (1997): Semiología de la obra dramática. Madrid: Arco Libros.

GENETTE, Gérard (1982): Palimpsestes. París : Seuil.

KRISTEVA, Julia (1980): Desire in Language: A Semiotic Approach to Literature and Art, L.S. Roudiez (ed.), Oxford: Blackwell.

RAGUÉ ARIAS, Maria Josep (1986): Clitemnestra. Barcelona: Editorial Millà.

ROIG, Montserrat (1991): Digues que m'estimes encara que sigui mentida. Barcelona: Edicions 62.

ROIG, MONTSERRAT (1992): Reivindicació de la senyora Clito Mestres. Seguit de El mateix paisatge. Barcelona: Edicions 62.

SHOWALTER, Elaine (1986): "Feminist Criticism in the Wilderness", en The New Feminist Criticism: essays on women, literature and theory. Elaine Showalter (ed.), Virago: Londres, pp. 243-270.

ZAVALA, Iris (1996): Escuchar a Bajtin. Madrid: Montesinos. 